\title{
Construções Identitárias de Psicólogos em NASF: Reflexões para a Prática Profissional
}

\author{
Fernanda Gomes Vasconcelos ${ }^{1}$ \\ ${ }^{1}$ Universidade Federal de Pernambuco, PE, Brasil.
}

\author{
Renata Lira dos Santos Aléssio ${ }^{1}$ \\ ${ }^{1}$ Universidade Federal de Pernambuco, PE, Brasil.
}

Resumo: Este artigo teve como objetivo analisar a construção de identidades profissionais de psicólogos no contexto de atuação em Núcleos de Apoio à Saúde da Família (NASF), a partir da dimensão identitária das representações profissionais. Foram realizadas entrevistas com oito psicólogos que atuam em NASF, na cidade do Recife/PE, divididas em duas etapas: a primeira do tipo entrevista narrativa, e a segunda do tipo semiestruturada, orientada por um roteiro, ambas realizadas em um mesmo encontro. As entrevistas foram áudio-gravadas e transcritas na íntegra em formato textual. Os dados foram analisados à luz do método fenomenológico para estudos em Psicologia. Esta análise foi guiada pela organização dos dados a partir de cinco etapas, que resultaram em unidades de significado, dentre as quais foi analisada no artigo a unidade $O$ psicólogo no NASF. Verificou-se que a visão hegemônica da Psicologia atrelada ao contexto da clínica privada produz uma cultura profissional que direciona as demandas para essa categoria e orienta as representações profissionais, bem como a construção de identidades e práticas profissionais. Os profissionais fizeram alusão a recursos da atuação tradicional de cunho individual como um dos meios de resolução do conflito entre a atuação demandada em NASF e suas construções identitárias. À guisa de conclusão, verificou-se que havia para esses profissionais um imperativo de manutenção de uma coerência que sustentasse a identidade profissional, atrelada ao consumo da cultura profissional, mas que se demonstrou, pela via da incoerência, como inconsistente para efetivação de política de atenção básica na saúde.

Palavras-chave: Identidade Profissional, Representações Profissionais, Psicologia; Núcleo de Apoio à Saúde da Família. 


\title{
Identity Constructions of Psychologists in NASF: Reflections for Professional Practice
}

\begin{abstract}
This article aimed to analyze the construction of professional identities of psychologists in the context of working in Family Health Support Centers (NASF in Brazil), based on the identity dimension of professional representations. Interviews were conducted with 8 psychologists who work in NASF, in the city of Recife/PE, and divided into two stages: the first one of the narrative interview type, and the second of the semi-structured interview type, guided by a script, both were applied in the same meeting. The interviews were audio-recorded and fully transcribed into textual format. Data were analyzed based on the phenomenological method for studies in Psychology. This analysis was guided by the organization of data into five stages, which resulted in units of meaning, among which the unity The Psychologist in NASF was analyzed. It was verified that the hegemonic vision of Psychology, linked to the context of the private clinic, produces a professional culture that directs the demands to this category and guides the professional representations, as well as the construction of professional identities and practices. The professionals alluded to traditional resources of individual character as one of the means of resolving the conflict between the action demanded in NASF and their identity constructions. As a conclusion, it was verified that there was a need for these professionals to maintain a coherence that would support professional identity, linked to the consumption of professional culture; however, it showed to be inconsistent for the effective implementation of the basic health care politic.
\end{abstract}

Keywords: Professional Identity, Professional Representations, Psychology, Family Health Support Centers.

\section{Construcciones Identitarias de Psicólogos en NASF: Reflexiones para la Práctica Profesional}

Resumen: Este artículo tuvo como objetivo analizar la construcción de identidades profesionales de psicólogos en el contexto de actuación en Núcleos de Apoyo a la Salud de la Familia (NASF), a partir de la dimensión identitaria de las representaciones profesionales. Se realizaron entrevistas con 8 psicólogos que actúan en NASF, en la ciudad de Recife / PE, divididas en dos etapas: la primera del tipo entrevista narrativa, y la segunda del tipo semiestructurada, orientada por un itinerario, ambas realizadas en un mismo encuentro. Las entrevistas fueron audio-grabadas y transcritas en su totalidad en formato textual. Los datos fueron analizados a la luz del método fenomenológico para estudios en Psicología. Este análisis fue guiado por la organización de los datos a partir de cinco etapas, que resultaron en unidades de significado, entre las cuales se analizó en el artículo la unidad El psicólogo en el NASF. Se verificó que la visión hegemónica de la Psicología ligada al contexto de la clínica privada produce una cultura profesional que dirige las demandas para esa categoría y orienta las representaciones profesionales, así como la construcción de identidades y prácticas profesionales. Los profesionales hicieron alusión a recursos de la actuación tradicional de cuño individual como uno de los medios de resolución del conflicto entre la actuación demandada en NASF y sus construcciones identitarias. A la luz de la conclusión, se verificó que había para estos profesionales un imperativo de mantener una coherencia que sostuviese la identidad profesional, ligada al consumo de la cultura profesional, pero que se demostró, por la vía de la incoherencia, como inconsistente para la efectividad de política de atención básica en la salud.

Palabras clave: Identidad Profesional, Representaciones Profesionales, Psicología, Núcleo de Apoyo a la Salud de la Familia. 


\section{Introdução}

O Núcleo de Apoio à Saúde da Família (NASF) éum dos serviços que compõem a atenção básica, implantado em 2008, com o objetivo de ampliar e reforçar as ações e resolubilidade das equipes de saúde da família, atuando de forma integrada e apoiando os profissionais de saúde da família (Portaria $n^{\circ} 2.488,2011$ ). De acordo com a Portaria no 154 (2008), que cria os NASFs, a Psicologia faz parte das categorias profissionais que devem compor esta equipe, sendo designada a desenvolver atenção à saúde mental. Dessa forma, os profissionais são convidados a atuar em um contexto repleto de desafios, não só pelo caráter recente da instituição do citado serviço, como também pela necessidade em construir uma prática pautada pelo viés da ação coletiva, indo de encontro com a história da constituição dessa categoria no Brasil, marcada pelas práticas de cunho individual e privado (Dimenstein, 2001; Ferreira Neto, 2011).

De acordo com Santos (2015), o aumento da produção acadêmica relativa à inserção da Psicologia na atenção básica ocorreu após a publicação da Portaria $n^{\circ} 154$ (2008). É possível encontrar na literatura uma gama de trabalhos que se dedicam à discussão da atuação da Psicologia na atenção primária, apontando como principais entraves ao desenvolvimento de intervenções psicológicas, nesse nível de atenção, a dificuldade do trabalho em equipe, a ênfase na abordagem clínica tradicional, a baixa adesão dos usuários aos tratamentos propostos e o descompasso entre atuação psicológica e os pressupostos do Sistema Único de Saúde - SUS (Dimenstein, 2000; Dimenstein et al., 2009; Dimenstein, 1998; Jimenez, 2011; Nepomuceno, 2014; Oliveira, Silva, \& Yamamoto, 2007; Santos, 2015).

Mesmo diante de um vasto número de produções acadêmicas acerca da atuação da Psicologia na atenção primária, os resultados das pesquisas acessadas apontam que é necessário dar continuidade aos estudos na área, a fim de consolidar as práticas psicológicas.

Retomando um dos entraves apontados pela literatura - a atuação na atenção primária a partir do modelo da clínica tradicional - verifica-se que esta é uma questão que demanda atenção dos pesquisadores da área, uma vez que, dada a sua complexidade, é geradora de polêmicas e incertezas tanto no campo teórico como no campo prático. Justifica-se a ocorrência de tal modelo de atuação por haver uma transposição da prática psicológica de consultório para a saúde pública, além da deficiência na formação dos profissionais, do suposto status que a clínica tradicional pode proporcionar ao psicólogo e da configuração das políticas públicas, que não apresentam claramente definições das atuações e do papel dos psicólogos na saúde pública (Böing, Crepaldi, \& Moré, 2009).

As ideias referentes às práticas dos psicólogos estão voltadas para o conhecimento da intimidade e individualidade dos indivíduos, caracterizando um dos aspectos mais importantes da cultura profissional, que responsabiliza a Psicologia a compreender o outro a partir do modo de ser do sujeito. A cultura profissional pode ser compreendida como o conjunto de ideias, visão de mundo e estilos profissionais que são adotados por um grupo específico, determinando sua adesão e preferência por certos modelos de atuação (Dimenstein, 2000). Assim, à Psicologia é atribuída, de forma limitada, a função de explicar processos psicológicos em situações em que reinam dúvidas sobre questões ditas enigmáticas (Scarcelli \& Junqueira, 2011).

Essa visão hegemônica não só contribui com a representação social da categoria - atuar em consultórios privados, centrado na "escuta clínica" dirigida ao indivíduo (Lima \& Nunes, 2006) - no contexto brasileiro, como também com a construção das representações profissionais elaboradas pelos psicólogos em suas práticas, perspectiva teórica que orienta esse estudo.

De acordo com Blin (1997) para se comunicar, se adaptar e agir em uma situação profissional, as pessoas constroem representações profissionais partilhadas com outros, de forma que toda atividade profissional se situa em interações múltiplas entre os sujeitos e os grupos, que pressupõem de tais representações profissionais. Essas representações são veiculadas pelas imagens e palavras que circulam no discurso e materializam-se nas práticas. São fortemente contextualizadas, uma vez que $o$ ator que as exprime o faz a partir de sua inserção em uma instituição, de seu meio de trabalho, destacando-se que são mais um veículo grupal do que individual (Blin 1997).

As representações profissionais definem as identidades profissionais e protegem as especificidades dos grupos intra e interprofissionais. Possuem três dimensões: funcional (cognições sobre os objetos significativos da prática); contextual (cognições sobre a organização e a instituição); e identitária (cognições sobre os objetos ligadas ao jogo 
identitário entre o profissional ideal e o profissional real, diz respeito a motivações, projetos, competências profissionais que levam à construção de um saber profissional e orientam condutas e práticas) (Abdalla et al., 2010; Blin, 1997).

Dentre as funções das representações profissionais destaca-se que estas participam, junto com outras cognições, da construção de um saber profissional. Esse saber, diferente do científico e do saber do senso comum, uma vez que é produzido dentro do contexto da atividade profissional, permite aos atores compreender e agir sobre a realidade a partir de um princípio de economia cognitiva. Ou seja, constitui a base da comunicação profissional, sem que seja necessário aos atores defini-las, e permite a resolução de problemas cotidianos que envolvem as atividades profissionais, sem que seja necessário grande dispêndio cognitivo (Blin 1997).

A análise das representações mobilizadas dentro de um quadro de situações profissionais envolve a inserção dos indivíduos em seu campo profissional e os valores e práticas associadas a essa inserção (Blin 1997). Tendo em vista que do psicólogo no NASF espera-se a construção de respostas eficientes para as mais variadas demandas existentes no território (Jimenez, 2011), o profissional é colocado diante de uma gama de possibilidades de intervenção (individual, coletiva, institucional etc.) que pode desestabilizar certas identificações previamente construídas e sustentadas por representações profissionais que orientam suas práticas.

O presente artigo apresenta uma parte dos resultados obtidos através de uma pesquisa que teve como objetivo investigar as representações profissionais de psicólogos que atuam em NASF. Assim, buscou-se compreender em que medida os psicólogos mantêm e modificam identidades profissionais, calcadas em representações profissionais, em função das práticas em NASF. Para tanto, este artigo tem como objetivo analisar a construção de identidades profissionais de psicólogos no contexto de atuação em NASF, a partir da dimensão identitária das representações profissionais.

\section{Método}

\section{Participantes}

A pesquisa foi desenvolvida com oito psicólogos de NASF, da cidade de Recife, Pernambuco. Os 94 bairros da cidade de Recife estão divididos em oito
Regiões Político-Administrativas (RPA), sendo, para o setor de saúde, cada uma correspondente a um Distrito Sanitário (DS). Todos os DS são compostos por serviços de saúde de nível primário, secundário e terciário de atenção, destacando-se, no nível primário, a existência de 122 Unidades de Saúde da Família e 20 equipes NASF. Nos níveis secundário e terciário, a atuação de psicólogos se dá, prioritariamente, nos 17 Centros de Atenção Psicossocial e em 12 Policlínicas, onde ocorre o atendimento ambulatorial (Secretaria de Saúde do Recife, 2014). Foram escolhidos psicólogos de oito equipes NASF para participar da pesquisa, um de cada DS, com o intuito de contemplar todas as regiões de saúde de Recife, uma vez que estas diferem em aspectos demográficos e sociais, fatores que poderiam influenciar o delineamento das intervenções da equipe, elaboradas a partir das necessidades do território. Em respeito à manutenção do anonimato dos participantes, as informações sobre nome, idade, entre outras, estão omitidas nesta pesquisa. Os nomes apresentados nos Resultados e Discussão são fictícios.

\section{Aspectos éticos}

A pesquisa foi aprovada pelo Comitê de Ética em Pesquisa da Universidade Federal de Pernambuco (UFPE), sob número de CAAE 47092615.4.0000.5208.

\section{Instrumentos e materiais de coleta de dados}

A coleta dos dados foi realizada a partir de entrevistas qualitativas divididas em dois momentos: o primeiro em que a entrevista foi do tipo narrativa e o segundo em que foi do tipo semiestruturada. No presente artigo serão analisados os dados da segunda etapa da coleta, que resultaram em informações sobre as práticas dos profissionais inseridos em NASF.

\section{Procedimento de análise de dados}

Para análise dos dados obtidos a partir das entrevistas foi utilizado o método fenomenológico para estudos em Psicologia. Esse método, amplamente discutido e utilizado por Trindade, Menandro e Gianórdoli-Nascimento (2007), busca analisar as percepções e concepções dos indivíduos estudados acerca de determinado fenômeno. Dessa forma, tal metodologia envolve uma análise do caso a caso, o que justifica amostras intencionais que vão levar a um grupo 
de indivíduos mais definido, para quem o estudo seja significativo, não havendo intenção em trazer resultados prescritivos (Chapman \& Smith, 2002). O interesse não é no individual, na subjetividade, e sim em como diferentes pessoas (diferentes psicólogos) vivenciam situações em comum (atuação profissional no NASF). Para análise dos dados à luz da metodologia fenomenológica para estudos psicológicos, Trindade, Menandro e Gianórdoli-Nascimento (2007) elencam cinco fases: fase 1 - transcrição integral das entrevistas; fase 2 - construção de unidades de significados; fase 3 reorganização das entrevistas de acordo com as unidades; fase 4 - conversão das falas literais para uma linguagem padronizada; fase 5 - construção de uma estrutura textual para cada entrevistado. Os dados analisados neste artigo compõem a unidade de significado "O psicólogo no NASF", que se subdivide em: demandas ao psicólogo e condução da prática e resolução de conflitos. Esta unidade está diretamente articulada à dimensão identitária das representações profissionais, prisma analítico utilizado na discussão dos resultados.

\section{Resultados e discussão}

Partindo da concepção de Blin (1997) acerca dos campos de atividades profissionais enquanto produtores de identidades durante o curso do processo de socialização, indaga-se se no NASF os profissionais de Psicologia constroem identidades específicas, que se diferenciam das identidades de psicólogos em outros contextos de atuação. Segundo este autor, a dimensão identitária refere-se a cognições sobre objetos que estão ligados ao jogo identitário entre profissional ideal e profissional real, a motivações, projetos e competências profissionais que levam à construção de um saber profissional e orientam condutas e práticas.

Nos relatos dos profissionais entrevistados, o psicólogo no NASF deve estar disponível a atender uma demanda mais ampla em relação ao espaço de consultório individual, utilizando este último contexto de atuação como referência e meio de comparação para o desenvolvimento de práticas no NASF. Assim, no jogo identitário profissional ideal versus real, os entrevistados se utilizaram de referenciais conhecidos, o atendimento individual, para repensar a prática nesse novo contexto. Elementos "velhos" se unem a elementos "novos" em busca de uma estabilização entre identidades e práticas.
Em uma pesquisa feita pelo Centro de Referência Técnica em Psicologia e Políticas Públicas (CREPOP) (Conselho Federal de Psicologia, 2010) sobre as práticas dos psicólogos na atenção básica, foi apontado que a atuação desses profissionais ainda vinha se configurando e se consolidando como uma prática da Psicologia, tanto para os profissionais de saúde, incluindo os próprios psicólogos, como para os usuários dos serviços. Ao discutir sobre a inserção do psicólogo no NASF, Jimenez (2011) destaca que há uma expectativa de que esta categoria responda de forma satisfatória a uma diversidade e complexidade de demandas, fator que contribui com os entraves na construção de práticas nesse contexto interventivo. Assim, tal expectativa pode acarretar aos profissionais conflitos entre o profissional ideal, aquele que faz uso da escuta clínica em intervenções individuais, e o profissional real, que precisa dar conta das demandas difusas da atenção básica.

Se o que está em jogo é o conflito entre a função do psicólogo (ideal) e a função da Psicologia no NASF (real), parece que as equipes de saúde da família reforçam este embate ao direcionar à categoria "casos de saúde mental", que, segundo Scarcelli e Junqueira (2011), são comumente atrelados ao campo psi. A expectativa das equipes de saúde da família em relação à atuação do psicólogo é um ponto de entrave. O psicólogo no NASF é colocado pela equipe de saúde da família como o profissional que irá dar conta do sofrimento do outro, pois tal sofrimento é insuportável para os outros profissionais. Verificou-se fortemente na fala dos entrevistados o caráter difuso das demandas que chegam para os psicólogos no NASF, como nos exemplos: "Agora dos casos de saúde mental, aí meu amigo, você vai ter toda a diversidade possível e imaginável, você vai ter todas elas. [...] É o mais variado possível de casos" (Fábio);

"Na equipe de saúde, mas principalmente com os ACSs, que é tudo assim 'descompensou, chama a psicóloga', sabe? E assim, a questão de um acolhimento, de você escutar o outro, de você se mostrar disponível pro outro" (Júlia).

Para Jimenez (2011), a demanda é um problema para os psicólogos na atenção básica, pois não há métodos, técnicas e respostas prontas a elas que atenderão todas as necessidades das comunidades com que trabalham. Atrelado a isso, os profissionais das equipes de saúde da família possuem as suas próprias representações da Psicologia, que os coloca em 
posição de demandar aos psicólogos intervenções de cunho individual, que partem da cultura profissional construída em volta da noção do psicólogo como aquele que acolhe, escuta e auxilia os sujeitos a conhecerem a si mesmos: "Olhe, tem os atendimentos individuais que no meu caso é, responde pelo maior número das demandas das atividades, porque pelas razões que eu já disse né que a demanda é muito grande, né? Tem pessoas que vem pra $\mathrm{N}$ coisas, mas que precisa de uma escuta" (João).

Todo mundo tem a sua dor, mas são coisas desse nível, que precisam dessa escuta. Um acolhimento ou então uma escuta que você consiga dizer alguma coisa para aquela pessoa que ela consiga respirar, naquela hora. Pronto, eu acho que essa é a grande demanda que chega mais pra gente. Essa escuta (Carlos).

Do psicólogo no NASF espera-se a construção de respostas eficientes, junto com as equipes, para as mais variadas demandas de saúde mental existentes no território (Jimenez, 2011). Assim, o profissional é colocado diante de uma gama de possibilidades de intervenção (individual, coletiva, institucional, etc.) que pode desestabilizar certas identificações previamente construídas. Mesmo diante dessas dificuldades em torno das demandas para a Psicologia, Jimenez (2011) aponta que existem possibilidades de ampliação das intervenções através de recursos que agregam instrumentos da clínica com contribuições das abordagens social e institucional, e sugere:

As abordagens em domicílio por meio de equipes volantes e o matriciamento são importantes ferramentas de cuidado para com os sujeitos e seus familiares, podendo ainda ser aliadas ao olhar criterioso e analítico para com a demanda, enquanto expressão subjetiva de sofrimento de uma dada coletividade (Jimenez, 2011, p. 132).

No contexto da atenção básica os profissionais dispõem de um rol de práticas que são, ao mesmo tempo, produto e processo das representações profissionais construídas ao longo da atividade laborativa. Para Blin (1997), um determinado conjunto de representações profissionais corresponde a um modelo profissional que, por sua vez, envolve esquemas de ação, conceituações, valores, finalidades, atitudes e conhecimentos que se unem para direcionar escolhas e justificar ações. Através das falas dos profissionais foi possível perceber a existência de um modelo de atuação psicológico pautado pelo viés tradicional, muitas vezes utilizado para justificar as práticas de cunho individual realizadas por eles frente às demandas presentes no NASF: “

Não é que eu faça ambulatório né? Mas às vezes a gente tem que atender aquela pessoa que tá precisando naquele momento de uma abordagem breve, focal mesmo. Entendeu? E o pessoal é muito carente, não tem pra onde ir" (João); "O pessoal sempre diz 'ah, no NASF não pode fazer ambulatório'. Não é ambulatório, porque de fato, não é ambulatório. Mas você precisa ter essa escuta e às vezes precisa de um acompanhamento um pouquinho maior" (Laura).

Nesse sentido, há um retorno aos referenciais "velhos" da prática, que se fazem presentes através da justificativa de sua importância no novo contexto. De acordo com Santos (2016), na pesquisa de Alves (2016) esta última autora afirma que existem alguns paradigmas de atuação que misturam velhas e novas práticas atreladas ao passado e ao presente das políticas públicas e à disputa entre as concepções de saúde a partir da perspectiva da promoção e da perspectiva biomédica.

Nos resultados da pesquisa foram colhidos relatos de profissionais que se utilizavam da mistura entre velhas e novas práticas, e de outros que permaneceram ligados exclusivamente às práticas tradicionais. João, por exemplo, destacou o modelo de atendimento ambulatorial como aquele com o qual se identificava, pois via resultados. Este mesmo profissional, talvez em busca de uma manutenção identitária atrelada ao grupo em que se sentia pertencente, defendeu a reprodução do modelo de atendimento ambulatorial no NASF.

Veja bem, a dificuldade das salas como eu disse. Ai eu resolvi fazer uma escala nas unidades em que eu tivesse naquele instante uma sala disponível. Porque a gente não vai atender na recepção, não vai atender do lado de fora. A gente precisa de um local preservado né? Que garanta no mínimo um mínimo de sigilo né. [...] Então por conta disso aí eu fiquei com esses horários fixos nessas unidades, que isso não quer dizer que se precisar de outro dia pra eu ir pra uma visita, um atendimento emergencial, desde que tenha sala, 
eu não vá, eu vou. [...] Porque eu venho, já marco a agenda antes entendeu? Então hoje eu tenho esses locais, dias e horários fixos nessas unidades e eu achei que ficou, achei não, tenho certeza que funciona, entendeu? (João).

Para Dimenstein (2000), quando há transposição de práticas tradicionais para o âmbito da saúde pública e o atendimento a camadas populares, os profissionais estão partindo do pressuposto de que tal população compartilha de uma mesma visão de mundo e que possuem uma mesma representação de saúde e doença que eles, baseando-se no modelo de subjetividade que pauta das formas de atuação tradicionais.

A autora alega que este tipo de prática terapêutica só é eficaz quando funciona enquanto sistema simbólico para o sujeito, ou seja, quando é capaz de lhe oferecer uma explicação, um sentido para seu sofrimento e vivências. Assim, psicólogo e paciente devem compartilhar de um mesmo projeto psicoterápico. De forma geral, os profissionais reconheceram que não fazia parte do papel do psicólogo no NASF a realização do acompanhamento individual nos moldes de ambulatório ou consultório particular, mas em muitas passagens de seus relatos destacaram a intervenção individual como estratégia mais adequada a certos casos, como os descritos por Mariana como mais graves.

Eu enquanto psicóloga assim, a demanda é enorme aqui dentro da, da unidade, ou como das outras também. A gente não consegue dar conta, não consegue, porque a gente aqui não faz ambulatório. Embora que, apesar de que os ambulatórios estão com as demandas muito né? Tá no gargalo, não estão atendendo. Então aqueles casos como, por exemplo, pânico, que a gente tá vivenciando demais, sobrepeso, é, crianças com dificuldades nas escolas, é... Esses assim, a gente faz um acompanhamento, sabe? (Mariana).

O conflito presente na atuação em NASF referente aos atendimentos individuais levou alguns profissionais à dicotomização entre intervenções grupais e intervenções individuais, colocando-as em lugares contrários, ou sendo uma substituída pela outra a fim de dar conta do alto número de casos presentes.
Psicologia você vai passar um tempão lá, toda semana indo, pra fazer o seu acompanhamento. Então não dá resposta em termos de números. Aí se passou um tempo "não, tem que formar grupo, tal tal". Mas nem tudo se trabalha em grupo. Tem situações que você tem que aprofundar no indivíduo mesmo (Carlos).

Por exemplo, hoje, a gente juntou, e a gente fez esse grupo porque eu via que tinha uma demanda muito grande de mulheres que estavam em sofrimento, né? Sofrimento mental que não sabia conduzir ou que tinha perdido o sentido dessa vida delas, ou que tinham enfim... Então eram mulheres com histórias muito parecidas e a gente fazendo essa escuta. A gente fazendo essa escuta regularmente no consultório, eu digo: "vamo juntar essas mulheres, vamo fazer um grupo” (Ana).

A contraposição entre atendimentos individuais e em grupo parece ser uma questão assentada na dicotomia social-individual, que demarca intervenções distintas a indivíduos de diferentes classes sociais. Velho (1981) propõe uma hipótese, que mesmo tendo sido lançada há décadas atrás, se faz pertinente para esta discussão, referente ao atendimento $p s i$ a populações de classes sociais diferentes daquelas a que pertencem os profissionais. Mesmo correndo o risco de cair em generalizações excessivas, o autor aponta que profissionais $p s i$ (psiquiatras, psicanalistas, psicólogos) possuem dificuldades em lidar com indivíduos de classes e subculturas diferentes das suas, que são as que portam os "saberes oficiais". Por mais que tenha pretensões de serem objetivos e universais, esses saberes, ou campos de conhecimento, são balizados e marcados culturalmente. As referências aos padrões de normalidade, à avaliação de trajetórias e de bem-estar pessoal partem de uma visão de mundo contaminada por ideias de eficiência e produtividade do "individualismo burguês" (Vellho 1981). Um dos participantes levanta essa questão em sua fala:

Pelas relações que se constroem, assim, no modelo que já vem, é, de formação autoritária que produz na, na organização da equipe NASF, das equipes de saúde da família, uma relação autoritária com as pessoas, porque é como se toda educação em saúde, implicitamente, a equipe 
de saúde da família tivesse dizendo: "vocês são idiotas! Vocês não conseguem... É... Vocês não conhecem sobre saúde, sobre a vida de vocês, sobre saúde". [...] E tem preconceito com pobre também, sabe? Preconceito! Eu acho que tem um elitismo da... Da classe, principalmente, médica ainda, que tá posto, nesse sentido (Fábio).

A citação de Velho (1981) endossa o argumento do participante: "Mas, em geral, a definição de realidade com que trabalham os terapeutas é bastante arbitrária, restrita e pouco sensível à diversidade das experiências sócio-culturais” (p. 30). O ideário individualista possibilitou o desenvolvimento de saberes dentro de um campo psi voltado para um segmento da sociedade moderna, a classe média urbana (Dimenstein, 2000). Nesse mesmo sentido, Jimenez (2011) afirma que existe um risco em, generalizando as demandas através da compreensão clínica tradicional individualizante, o psicólogo se colocar como uma extensão do Estado que oprime e violenta seus cidadãos, promovendo a patologização e a manutenção das desigualdades e injustiças sociais.

A mudança da clientela e demanda (do privado para o público) não seriam problema se não houvessem limitações teóricas e técnicas específicas de sua formação, que fundamentam seus modelos de atuação, sua identidade e cultura profissional. Assim, profissionais e pacientes, no campo da saúde pública, são provenientes de diferentes grupos sociais, o que implica em portarem diversas culturas somáticas (Dimenstein, 2000).

Em outras palavras, a relação que os indivíduos mantêm com seus corpos, a forma de habitar, expressar e verbalizar as sensações corporais, tudo isso é fruto de um habitus corporal, de um conjunto de práticas sociais características de uma classe, logo escapam a qualquer tentativa de universalização e padronização. Estas questões são importantes pois nos ajudam a compreender os inúmeros impasses e identificar as raízes de um certo mal-estar estabelecido entre pacientes e terapeutas no campo da assistência pública à saúde, bem como a baixa eficácia das terapêuticas e o alto índice de abandono dos tratamentos por parte dos pacientes (Dimenstein, 2000, p. 110).
Segundo Yamamoto (2012), a atuação psicológica tem se orientado muito mais pela oferta de serviços já prontos, do que pela construção de respostas a partir das demandas das populações atendidas. $\mathrm{O}$ autor questiona, então, se faltaria ao profissional de Psicologia a construção de novas práticas diante das demandas do campo social. E mais, se considerar as demandas da população é sinônimo de dar respostas às suas necessidades. Por exemplo, realizar atendimentos individuais no setor público de saúde, nos moldes da clínica privada, mesmo se esta for uma demanda da população, é o suficiente para aumentar o alcance social da profissão?

Os dados da pesquisa apresentada neste artigo não fornecem embasamento suficiente para responder a esse questionamento, mas que se faz importante à discussão por promover reflexões acerca da pertinência das intervenções das quais os participantes lançam mão em suas práticas. Dando possíveis direcionamentos a essa discussão, Yamamoto (2012) afirma que toda ação profissional deve ser qualificada tecnicamente, mas que a competência técnica em si não é uma condição suficiente, nem tampouco adequada a qualquer situação.

Tendo em vista que as representações são elaboradas através da ação e mantêm a identidade de um grupo, o exercício prático nos moldes clássicos de atuação da Psicologia direciona as representações profissionais dos psicólogos, reforçando a identidade profissional da categoria, vinculada ao atendimento de demandas individuais. Isso não quer dizer que não sejam feitos questionamentos e contestações desse modelo pelos profissionais, demarcando o caráter múltiplo e contraditório da identidade, sujeita a mudanças a partir das práticas. Nesse sentido, destaca-se a fala de Fábio, participante que narrou sua trajetória inserida dentro do contexto de atuação comunitária, interrogando a intervenção psicológica na atenção básica:

Mas tem uma coisa que eu tenho vivido na pele, que tem a ver com a prática da Psicologia no NASF, na estratégia de saúde da família. [...] É o acompanhamento individual a longo prazo. [...] Agora o que acontece, o NASF acaba se esquivando, se eximindo da responsabilidade de acompanhamento a longo prazo. Primeiro porque a equipe de saúde não faz isso a contento e segundo porque eles não querem se comprometer mesmo de 
pegar e tocar, não daria conta se fosse fazer sozinho esse acompanhamento (Fábio).

Fábio propõe pensar que o acompanhamento individual é possível e necessário de ser feito no NASF, entretanto não nos moldes do ambulatório, nem tampouco no modelo de consultório privado. Um dos arranjos encontrados por ele, a partir de discussões fomentadas em reuniões de categoria (dos psicólogos dos NASF de Recife) para justificar sua prática, foi o seguinte:

Faço escuta de 15 em 15 dias. Não é nessa perspectiva da Psicologia tradicional, individual, elitista, nem poderia ser (risos). Que de elitismo não tem nada, aquele usuário, aquele perfil, mas é um acompanhamento sistemático. [...] Porque também eu discuti toda essa questão nesse espaço mais psi. Nesse espaço mais psi, sabe? E acho que é legal que venha desse espaço psi mesmo porque eu acho que tem uma, uma tradição, vamos falar essa palavra, desse espaço da valorização da escuta, do individual, da escuta, do apoio mais individual. Que tem que ser repensado esse modelo clássico. [...] Não é a questão do divã, não é questão, mas é como a gente se insere na perspectiva da clínica ampliada, no cuidado individual sistemático do psicólogo do NASF na atenção básica, entendeu? (Fábio).

A reunião a que Fábio refere-se em sua fala ocorre mensalmente, com todos os psicólogos dos NASFs de Recife, e tem como objetivo discutir os entraves cotidianos e as saídas encontradas pelos profissionais, construindo e reforçando práticas em conjunto. A partir dessa problematização, Fábio abre a possibilidade de repensar práticas tradicionais, mobilizando construções identitárias e as representações profissionais do grupo.

Ainda para este participante, o acompanhamento individual por parte do NASF é potencializado quando há um vínculo com as equipes de saúde da família, uma vez que os casos que a Psicologia atende são complexos e demandam intervenções a longo prazo, de diversos saberes, fazendo-se necessária uma retaguarda de outros membros da equipe. Entretanto, verificou-se nas falas dos participantes, dificuldades que estes enfrentavam diante das equipes de saúde da família, tanto no tocante à implicação na realiza- ção das atividades coletivas, quanto no compartilhamento dos casos, muitas vezes direcionados para o profissional de Psicologia lidar de forma individual.

Outros participantes da pesquisa também apresentaram em seus relatos diferentes formas de lidar com o conflito instituído em relação ao atendimento individual na atenção básica. Flávia, por exemplo, relatou utilizar do recurso do encaminhamento como uma possibilidade de tratamento aos usuários, reforçando a ideia de que a psicoterapia é uma intervenção que garante resultados, visto que ocupa o caráter de "ideal de atuação", hierarquicamente superior a outras técnicas terapêuticas, o que faz com que o usuário seja sempre recebido pelo psicólogo como um forte candidato à psicoterapia (Lima \& Nunes, 2006) e que se esta não tem condições de ser realizada pelo psicólogo do NASF, deve ser garantida em outros espaços, como o ambulatório.

Eu tenho que encaminhar. Se é uma coisa, como já apareceram, principalmente, de uma pessoa que foi abusada na infância e ela tava com dificuldade de ter relacionamento sexual com o marido, e com dificuldade de fazer exame ginecológico, né? A intimidade dela assim bem reprimida. Então, é psicoterapia. Eu não tenho como ficar enrolando aqui, uma vez, uma vez no mês eu ver essa pessoa. Ela tem que toda semana ter o direito dela de ter o espaço clínico dela, psicológico (Flávia).

Neste ponto é válido destacar as dificuldades apontadas pelos profissionais em realizarem encaminhamentos de pacientes para atendimento ambulatorial, tendo em vista que o número de profissionais de Psicologia inseridos nas Policlínicas do município é reduzido em relação à demanda para este modelo de intervenção em acompanhamento. Além disso, os profissionais do NASF apontaram dificuldades em estabelecer uma parceria com os psicólogos no ambulatório, sendo necessário recorrer a relações de amizade em situações de encaminhamento que avaliam como mais graves.

Já Carlos, Júlia e Laura construíram práticas no NASF justificadas a partir de atuações em outros contextos. Esse fato corrobora com a proposição de Dubar (2006) de que as identidades não só estão atreladas às vivências dos atores dentro da instituição atual, mas 
têm a ver com aspectos biográficos, como suas trajetórias ao longo da vida profissional.

Eu no consultório não sou tão diretivo como sou, mas no NASF eu tenho que ser diretivo. Eu não vou ter um tempo determinado semanalmente com aquela pessoa, eu preciso empurrá-la um pouco. Então no NASF a gente faz essas pontuações, né? Claro que a gente tem que fazer a escuta pra ver onde vai pontuar pra surgir um efeito. Isso é a formação da gente que vai permitir isso. Mas a gente tem que ser um pouco diretivo. [...] A gente procura dar algumas sugestões, empurrar um pouco a pessoa. Pra ver se consegue ter algum efeito (Carlos).

Porque no consultório ali o, a pessoa fala, outra coisa, veja... uma coisa é você atender num setting terapêutico, você tem o tempo, a hora, tudo estabelecido e tudo, né... Você tem como se fosse uma espécie de controle. [...] Tipo eu não vou, quando eu faço uma intervenção, eu não vou esperar daqui uma semana pra atender aquela pessoa. É uma coisa mais diretiva. Sabe? É feito no hospital, porque no hospital pode ser que aquele paciente não esteja vivo amanhã, então você não tem muita coisa pra elaborar, muita coisa eu procuro levantar, trabalhar e amarrar naquilo (Júlia).

Às vezes a gente precisa sair e ter essa noção né, da sua função no NASF e no consultório, né, e no ambulatório. No ambulatório a gente vai poder fazer uma psicoterapia, a gente vai ter os horários, vai ter os dias, tudo direitinho. No NASF a gente pode ter os dias, pode ter os horários, pode fazer essa escuta ou na unidade ou num ponto que você precise fazer. [...] Eu percebo assim, no consultório fica bem mais fácil da gente ter uma escuta, porque você tá lá, tá tranquilo, né? Às vezes no NASF você vai precisar ouvir na rua, vai precisar ouvir em qualquer lugar porque aquela pessoa tá naquela... (Laura).

Para Lima e Nunes (2006), no campo da saúde pública o psicólogo atua "interferindo mais" e sendo "mais incisivo", diferenciando a prática neste contexto da atuação em consultório privado. Assim, os profissionais encontram esse arranjo no contexto de intervenção fora do conhecido enquadre tradicional, que tem horário marcado e sala reservada, a partir da referência a ele, ressaltando convergências e divergências entre ambos que os ajuda a elaborar a prática. Pode-se afirmar que as práticas desempenhadas pelos participantes no NASF relacionam-se aos sentidos que atribuem à sua função neste contexto e que, de acordo com Machado (2003), são elaborados diante de uma diversidade de papeis, a fim de obtenção de reconhecimento pelos pares. A referência do consultório, do ambulatório e do hospital para os entrevistados foi importante na delimitação da identidade profissional, no contexto do NASF, uma vez que possibilitou o estabelecimento de semelhanças e diferenças na atuação com a mudança de cenário. Ou seja, as experiências vividas ao longo das trajetórias dos profissionais promoveram a construção de representações profissionais ressignificadas dentro de um novo contexto, em comparação com outros familiares aos participantes. A identidade é, portanto, diferença e pertença (Dubar, 2006), logo, um mesmo ator porta diversas identidades profissionais a partir de identificações a grupos profissionais de pertença (Blin, 1997).

Na década de 1990, Martin-Baró (1997) publicou um trabalho sobre o papel do psicólogo no contexto centro-americano, levantando a discussão em torno da importância dos profissionais se questionarem criticamente a respeito do caráter de sua prática, ou seja, do papel que desempenham frente à sociedade, centrando-se na questão: a quem suas intervenções estão beneficiando? O foco, então, não seria os tipos das atividades praticadas (se é individual, se é grupal, comunitária etc.), e sim as consequências históricas concretas que estas produzem. Em um cenário mais recente, Lima (2005) propõe a atuação psicológica coletiva enquanto modelo adequado de prática na atenção básica. Sua perspectiva está de acordo com a de Dimenstein (2000) que aponta a fragilidade das intervenções individuais nesse contexto de atenção à saúde, quando transpostas do âmbito privado, acarretando em uma baixa vinculação dos usuários a essa proposta de tratamento. As colocações apresentadas pelos autores, mesmo que em momentos históricos e espaços geográficos distintos, se aproximam no que tange a necessidade de implicação social da prática psicológica, indicando que esta não é uma questão recente, nem exclusiva ao cenário brasileiro. 
Sendo assim, entende-se que a questão não se esgota na simples troca de intervenções individuais em função de atendimentos grupais, mas muito além disso, deve-se repensar que técnicas vêm sendo utilizadas e a serviço de quem, como sugere a fala de Ana, em que a participante justifica a criação de um grupo de mulheres no território em que atua, tendo em vista a demanda específica desta população que atendia.

Bleger (1984), em seu livro Psico-Higiene e Psicologia Institucional, apresenta colocações acerca da Psicologia clínica e sua necessária carreira social, que podem contribuir com essa temática que ainda se faz presente nos contextos atuais. Para Bleger (1984), o psicólogo clínico deve ser habilitado a realizar atividades psicoterápicas por ser o profissional melhor preparado técnica e cientificamente para esta tarefa. Por outro lado, considera que a carreira social será um fracasso se os psicólogos permanecerem ligados exclusivamente à terapêutica individual. Para ele a função social do psicólogo clínico deve ser a saúde pública e não unicamente a terapia. Defendendo esta ideia, o autor se utiliza do conceito de higiene mental, presente no campo da saúde pública, e que tem seus fundamentos na mudança da assistência psiquiátrica, em busca de condições mais humanas de cuidado que levam a uma possibilidade maior de cura. A higiene mental propõe o diagnóstico precoce de doenças mentais enquanto importante ferramenta que possibilita não só maiores taxas de cura, como também a diminuição do sofrimento e de tratamentos invasivos, além de prezar pela promoção da saúde (Bleger, 1984).

A psico-higiene é um ramo especial da higiene mental que interessa especialmente aos psicólogos, pois propõe intervir sobre o nível psicológico dos fenômenos humanos, a partir de métodos e técnicas derivadas do campo da Psicologia e da Psicologia Social. Um profissional que atua no campo da psico-higiene, portanto, intervém nos problemas sociais e nas condições de vida dos indivíduos, devendo ele ir ao encontro das pessoas em suas ocupações e tarefas cotidianas, e não esperar que elas venham até ele. Destaca que a psico-higiene não exclui o exercício privado da profissão. O psicólogo então, deve intervir em todos os aspectos e problemas concernentes à psico-higiene e não esperar que o indivíduo adoeça para tratá-lo (Bleger, 1984).

No trabalho realizado por Jimenez (2011), a autora tenta exemplificar a contribuição dos instru- mentos tradicionais da Psicologia na ampliação da compreensão das subjetividades para além do individual e na aplicação dos princípios do SUS. A autora destaca que a crítica à prática clínica psicológica no âmbito da atenção básica deveria ser dirigida a qualquer prática clínica, como a médica e a odontológica, que sejam exercidas de forma fragmentada e distante da realidade dos indivíduos atendidos. E destaca que há três grandes desafios a serem superados nesse nível de atenção: o trabalho interdisciplinar, as ações intersetoriais, e o desenvolvimento de instrumentos ou técnicas voltados para o território.

Destacando-se a atuação interdisciplinar, foi relatado pelos profissionais algumas dificuldades, bem como pontos positivos referentes à inserção em equipe, remetendo ao debate entre núcleo e campo, presente na atuação em NASF e na construção de identidades profissionais. De acordo com Campos (2000) o núcleo pode ser entendido como a identidade de uma área de saber e suas atuações na prática. Haveria, então, uma concentração de conhecimentos, saberes e práticas que delimitaria tal área. Já o campo traria uma imprecisão de limites, em que as profissões buscam em outras apoio para desenvolver suas tarefas práticas e teóricas (Campos, 2000).

Bom e aí tem a dimensão do que é do campo e o que é do núcleo, pra trazer para um campo em que todos dialogam, todos trabalham juntos, entendeu? Sem essa lógica do, do aprisionamento do saber, né? Que na verdade que é de mercado, "não, isso aqui é nosso, não pode saber isso", né? que a gente desconstrói completamente no NASF. Tem que desconstruir. Sem abrir mão vamos dizer assim, sem descaracterizar a identidade dos psicólogos, sabe? Mas é como se eu tivesse dizendo que para o psicólogo fortalecer sua identidade em parte ele tem que desconstruir sua identidade na formação, entendeu? E se abrir a isso. Ou pelo menos a ressignificar diante da sua prática tradicionalmente, sabe? (Fábio).

Por exemplo, se eu chego numa casa em que uma pessoa tá com diabetes descompensado, mas come açúcar e tudo mais, aí você pode dizer as complicações do diabetes, isso aí eu num vou tá invadindo o núcleo de saber da nutricionista, porque isso é um conhecimento geral, entendeu? [...] Então assim, a gente trabalha muito na ques- 
tão da promoção de saúde e de modo coletivo, mas em alguns casos, a depender da especificidade de cada caso aí vai aquela pessoa talvez, é... De um saber específico (Júlia).

$\mathrm{Na}$ atenção básica, muitas vezes, essa noção do que é do núcleo e do que é do campo fica difusa, pois os limites são tênues, fato que pode acarretar inquietações na prática profissional. Pensar o núcleo e o campo remete à discussão apontada por Deschamps e Moliner (2014) acerca do endo e exogrupo. Para esses autores o indivíduo, através da diferenciação com outros grupos, afirma sua identidade social e sua pertença ao endogrupo, reforçando sua autoimagem positiva. Quanto maior for o sentimento de pertença em relação ao seu grupo, maior será a tendência a diferenciar-se do exogrupo, caracterizando o primeiro como positivo em relação ao segundo (Deschamps \& Moliner, 2014). Como já discutido, a própria necessidade em repensar práticas psicológicas tradicionais levanta uma série de mobilizações identitárias e, além dessa reorganização interna ao grupo, é necessário também que o profissional se situe em relação às outras categorias, incluindo seus saberes e práticas, que circulam na atenção básica, além do saber popular que também representa um outro núcleo.

A identidade profissional, como visto, constitui-se como uma rede de representações profissionais que é ativada para responder a uma identificação e/ou diferenciação em relação a grupos profissionais (Blin, 1997). As representações construídas ao longo das trajetórias profissionais, articuladas aos contextos, também se fazem presentes diante das diferenciações dos psicólogos em relação a outras categorias. Nesse sentido, o discurso dos entrevistados tomou a direção de que no NASF é preciso saber qual o seu núcleo de atuação e quais os dos outros, a fim de que se possa transitar entre eles quando necessário, como apontado por Júlia em sua fala apresentada acima. O trânsito entre núcleo e campo é uma característica do contexto de trabalho em equipe interdisciplinar que o diferencia da atuação em outros contextos, como o consultório privado, sendo necessário ao profissional construir referenciais que acomodem novas formações identitárias.

Aí às vezes as pessoas dizem "poxa, às vezes eu me sinto fazendo uma coisa que não é minha” e o outro eu tô fazendo tipo assim.. né... eu sou psi aí tô fazendo uma coisa que é lá de serviço social e o serviço social faz uma coisa $p s i$ e na realidade a gente tá fazendo o da gente, mas como é todo mundo, às vezes, quando a gente matricia, a gente precisa fazer um pouquinho do outro sem perder a identidade da gente (Laura).

Assim, o limite da atuação psicológica no NASF não se restringe ao seu núcleo de saber e deve estar em constante negociação com o campo, construído a partir das especificidades de cada território. Nesse sentido, Jimenez (2011) destaca a importância de, na atenção primária, o profissional estar disponível a cuidar não só de indivíduos, e muito menos de forma compartimentalizada, mas cuidar também de territórios:

A inserção da Psicologia nos Núcleos de Apoio à Saúde da Família (NASF) por um lado resgatou a importância deste campo de saber para as ações na atenção básica à saúde, porém, por outro lado, a tarefa solicitada ao psicólogo é abordar o cuidado às pessoas em situação de sofrimento mental não apenas a partir do referencial individual e/ou familiar, mas incluindo também a aproximação permanente com as histórias dos territórios e com a decifração dos códigos inscritos nestes espaços vivos e carregados de afetos que interferem diretamente na produção de subjetividades, e, portanto, nos processos de saúde e adoecimento (Jimenez, 2011, p. 137).

O que Jimenez (2011) destaca, reforçando a discussão dos dados apresentada, é que o trabalho no território não é garantido pela transposição de abordagens para o contexto da moradia e das habitações dos indivíduos que constituem uma comunidade. Essa transposição linear sem que haja consideração com a densidade e textura histórica e política dos territórios é arriscada e perigosa, pois pode conduzir à normatização e ao moldar de corpos dóceis (Jimenez, 2011). Dessa forma, a complexidade é inerente ao trabalho no NASF que demanda, para além do cuidado ao sujeito, o cuidado ao território, desafio que se instaura para a Psicologia enquanto prática historicamente atrelada ao indivíduo. O olhar do profissional ao território em que se desenrolam as relações e por onde transitam os usuários aponta um possível caminho para o desenvolvimento de novas práticas psicológicas. 


\section{Conclusão}

Faz parte da cultura profissional da Psicologia o modelo hegemônico de prática calcado na noção de sujeito psicológico desenvolvida a partir do ideário individualista, que determina a adesão e preferência pela atuação do âmbito clínico privado, por sua vez reforçada pela formação universitária (Dimenstein, 2000). Nesse sentido, a escuta clínica é considerada a função primordial do psicólogo, estando tal concepção vinculada a esta cultura profissional da categoria.

Essa função do psicólogo encontrou conflitos nos relatos dos participantes acerca da prática em NASF. $\mathrm{O}$ debate girou primordialmente em torno dos atendimentos individuais no contexto da atenção básica, demarcando que esta é uma questão que está longe de ser resolvida. Os participantes defenderam o uso de intervenções de cunho individual, justificadas a partir de práticas conhecidas e desenvolvidas em outros contextos profissionais, como o consultório, o ambulatório e o hospital. Paralelo a isto, também reconheceram que as intervenções individuais não são suficientes para suprir as demandas e as necessidades que se apresentam no contexto do NASF, e que a transposição de práticas de forma linear de um contexto para o outro não garante $o$ alcance social da profissão. A vivência deste conflito no NASF impulsionou os participantes, não todos, a criar maneiras de conduzir seu trabalho, através de intervenções que apostaram na mistura entre novas e velhas práticas. Baseado na noção de Blin (1997) de que a empresa/instituição possui uma função identitária, verificou-se que os conflitos vividos pelos profissionais no NASF dirigem, ao mesmo tempo, mudanças e estabilizações nas identidades profissionais, que justificam as práticas.

Não é a intenção instaurar uma disputa entre intervenções individuais e coletivas a fim de decidir qual das duas se aplica melhor ao âmbito da atenção básica. Propõe-se repensar aquelas intervenções que, calcadas em uma demanda de outra ordem (da classe média atendida em consultórios privados), não devem ser transpostas ao público, no contexto do NASF. Com isso, é apontada a importância de transformar a clínica psicológica em uma prática engajada politicamente e historicamente.

Como indica Jimenez (2011), a abordagem psicológica na atenção básica deve possuir subsídios sensíveis à percepção e compreensão das coletividades e das instituições, que tanto abarcam como extrapolam as individualidades. O profissional deve estar atento ao território, munido de estratégias e ferramentas de intervenção frente a essas demandas. O saber psicológico deve ser confrontado com os problemas atuais vivenciados pelo povo, sendo urgente assumir a perspectiva das maiorias populares. Esse saber deve ser colocado a serviço de uma construção de sociedade em que o bem-estar da minoria não se faça em cima do mal-estar da maioria (Martín-Baró, 1997).

As afirmações contidas neste artigo são de caráter exploratório, tendo em vista os limites colocados pela complexidade das identidades profissionais enquanto objeto de estudo. Além disso, a via de acesso às identidades, representações e práticas profissionais a partir da fala dos participantes colhidas em um único encontro com cada um deles pareceu insuficiente para gerar dados que pudessem fornecer informações mais precisas. Todavia, a pesquisa cumpriu ao que se propôs, fomentando discussões propícias ao campo investigado e que abrem precedentes para o desenvolvimento de outras investigações. O estudo mais aprofundado sobre as práticas desenvolvidas por psicólogos no contexto do NASF pode fornecer apontamentos mais precisos no que se refere às possibilidades de atuação psicológica na atenção básica, favorecendo a consolidação de representações e identidades profissionais e auxiliando na demarcação da função do psicólogo neste cenário.

\section{Referências}

Abdalla, M. F. B., Souza, J. C., Mesquita, A., Pereira, A. F. G., Duarte, M. R., et al. (2010). Representações profissionais dos professores e o sentido do trabalho docente. In: Anais do IV Seminário Internacional de Pesquisa e Estudos Qualitativos. Rio Claro, SP: Sociedade de Estudos e Pesquisa Qualitativos. Recuperado de http://www.sepq.org. br/IVsipeq/anais/artigos/85.pdf

Alves, R. B. (2016). Entre a rodoviária e a prisão sem muros: Sentidos e práticas sobre violência para profissionais de uma rede assistencial (Tese de Doutorado). Universidade Federal do Espírito Santo, Vitória, ES, Brasil.

Bleger, J. (1984). Psico-higiene e psicologia institucional. São Paulo, SP: Artmed.

Blin, J.-F. (1997). Représentations, pratiques et identités profissionnelles. Paris: L’Harmattan. 
Böing, E., Crepaldi, M. A., \& Moré, C. L. (2009). A epistemologia sistêmica como substrato à atuação do psicólogo na atenção básica. Psicologia:Ciência e Profissão, 29(4), 828-845.https://doi.org/10.1590/S1414-98932009000400013

Campos, G. W. S. (2000). Saúde pública e saúde coletiva: Campo e núcleo de saberes e práticas. Ciência \& Saúde Coletiva, 5(2), 219-230. https://doi.org/10.1590/S1413-81232000000200002

Chapman, E., \& Smith, J. A. (2002). Interpretative phenomenological analysis and the new genetics. Journal of Health Psychology, 7(2), 125-130. https://doi.org/10.1177/1359105302007002397

Conselho Federal de Psicologia - CFP. (2010). Práticas profissionais de psicólogos e psicólogas na atenção básica à saúde. Brasília, DF: o autor. Recuperado de http://crepop.pol.org.br/novo/wp-content/uploads/2011/02/Praticas_ABS.pdf

Deschamps, J.-C., \& Moliner, P. (2014). A identidade em psicologia social: Dos processos identitários às representações sociais (2a ed.). Petrópolis, RJ: Vozes.

Dimenstein, M. (2000). A cultura profissional do psicólogo e o ideário individualista: Implicações para a prática no campo da assistência pública à saúde. Estudos de Psicologia, 5(1), 95-121. https://doi.org/10.1590/S1413-294X2000000100006

Dimenstein, M. (2001). O psicólogo e o compromisso social no contexto da saúde coletiva. Psicologia em Estudo, 6(2), 57-63. https:// doi.org/10.1590/S1413-73722001000200008

Dimenstein, M. (1998). O psicólogo nas Unidades Básicas de Saúde: Desafios para a formação e atuação profissionais. Estudos de Psicologia, 3(1), 53-81. https:// doi.org/10.1590/S1413-294X1998000100004

Dimenstein, M., Severo, A. K., Brito, M., Pimenta, A. L., Medeiros, V., et al. (2009). O apoio matricial em unidades de saúde da família: Experimentando inovações em saúde mental. Saúde e Sociedade, 18(1), 63-74. https://doi. org/10.1590/S0104-12902009000100007

Dubar, C. (2006). A crise das identidades: A interpretação de uma mutação. Porto: Afrontamento.

Ferreira Neto, J. L. (2011). Psicologia e políticas públicas: Novas questões para a formação. In: J. L. Ferreira Neto (Org.), Psicologia, políticas públicas e o SUS (pp. 23-49). São Paulo, SP: Escuta.

Jimenez, L. (2011). Psicologia na atenção básica à saúde: Demanda, território e integralidade. Revista Psicologia e Sociedade, 23(n. esp.), 129-139. https:// doi.org/10.1590/S0102-71822011000400016

Lima, M. (2005). Atuação psicológica coletiva: Uma trajetória profissional em unidade básica de saúde. Psicologia em Estudo, 10(3), 431-440. https://doi.org/10.1590/S1413-73722005000300011

Lima, M., \& Nunes, M. O. (2006). Práticas psicológicas e dimensões de significação dos problemas de saúde mental. Psicologia: Ciência e Profissão, 26(2), 294-311. https://doi.org/10.1590/S1414-98932006000200011

Machado, H. V. (2003). A identidade e o contexto organizacional: Perspectivas de análise. Revista de Administração Contemporânea, 7(n. esp.), 51-73. https://doi.org/10.1590/S1415-65552003000500004

Martín-Baró, I. (1997). O papel do psicólogo. Estudos de Psicologia, 2(1), 7-27. https://doi.org/10.1590/S1413294X1997000100002

Nepomuceno, L. B. (2014). A construção social da prática psicológica na atenção primária à saúde do SUS (Tese de Doutorado). Universidade Federal do Ceará, Fortaleza, CE, Brasil. Recuperado de http://www.repositorio.ufc.br/ bitstream/riufc/10650/1/2014_tese_lbnepomuceno.pdf

Oliveira, I. F., Silva, F. L., \& Yamamoto, O. H. (2007). A psicologia no programa de saúde da família (PSF) em Natal: Espaço a ser conquistado ou um limite da prática psicológica? Aletheia, (25), 05-19.

Portaria No 2.488, de 21 de outubro de 2011. Aprova a política nacional de atenção básica, estabelecendo a revisão de diretrizes e normas para a organização da atenção básica, para a estratégia saúde da família (ESF) e o programa de agentes comunitários de saúde (PACS). Recuperado de http://bvsms.saude.gov.br/bvs/saudelegis/ gm/2011/prt2488_21_10_2011.html

Portaria $N^{o} 154$ de 24 de janeiro de 2008. Cria os núcleos de apoio à saúde da família - NASF. Recuperado de http:// bvsms.saude.gov.br/bvs/saudelegis/gm/2008/prt0154_24_01_2008.html

Secretaria de Saúde do Recife. (2014). Plano Municipal de Saúde 2014 - 2017. Recife, PE. Recuperado de http:// www2.recife.pe.gov.br/sites/default/files/plano_municipal_de_saude_2015_revisado_menor.pdf

Santos, M. F. S. (2016). Um estudo acerca da cidadania feminina através da educação. In: Actes de la XI Conférence Internationale sur les Représentations Sociales. (Presented at the Representação Social na América Latina: História e Evolução). Marseille: Université d'Aix-Marseille. 
Santos, W. T. M. (2015). Da precarização do trabalho às potencialidades do cuidado: A inserção de profissionais da psicologia nos núcleos de apoio à saúde da família (Tese de Doutorado). Programa de Pós-Graduação em Psicologia, Instituto de Psicologia, Universidade de São Paulo, São Paulo, SP, Brasil.

Scarcelli, I. R., \& Junqueira, V. (2011). O SUS como desafio para a formação em Psicologia. Psicologia: Ciência e Profissão, 31(2), 340-357. https://doi.org/10.1590/S1414-98932011000200011

Trindade, Z. A., Menandro, M. C. S., \& Gianordoli-Nascimento, I. F. (2007). Organização e interpretação de entrevistas: Uma proposta de procedimento a partir da perspectiva fenomenológica. In: M. M. P. Rodrigues, \& P. R. M. Menandro (Orgs), Lógicas metodológicas: Trajetos de pesquisa em psicologia (pp. 71-92). Vitória, ES: GM Gráfica.

Velho, G. (1981). Individualismo e cultura: Notas para uma Antropologia da sociedade contemporânea. Rio de Janeiro, RJ: Zahar.

Yamamoto, O. H. (2012). 50 anos de profissão: Responsabilidade social ou projeto ético-político? Psicologia: Ciência e Profissão, 32(n. esp.), 6-17. https://doi.org/10.1590/S1414-98932012000500002

Fernanda Gomes Vasconcelos

Especialista em Psicologia em Saúde Mental pela Universidade de Pernambuco, Recife - PE. Brasil. Mestranda do Programa de Pós-Graduação em Psicologia da Universidade Federal de Pernambuco, Recife - PE. Brasil.

E-mail: fernandagvas@gmail.com

(iD https:// orcid.org/0000-0001-8030-4220

Renata Lira dos Santos Aléssio

Doutora em Psicologia pela Universidade de Provence Aix Marseille I, Aix-Marceille I, França. Docente do Programa de Graduação em Psicologia da Universidade Federal de Pernambuco, Recife - PE. Brasil.

E-mail: renatalir@gmail.com

(iD https:// orcid.org/0000-0001-8548-2771

Endereço para envio de correspondência:

Avenida Conselheiro Rosa e Silva, 1241, apartamento 801, Aflitos. CEP: 52050-345.

Recife - PE. Brasil.

Recebido 19/01/2017

Reformulado 18/12/2018

Aceito 15/01/2019

Received $01 / 19 / 2017$

Reformulated $12 / 18 / 2018$

Approved 01/15/2019

Recibido 19/01/2017

Reformulado 18/12/2018

Aceptado 15/01/2019

Como citar:Vasconcelos, F. G., \& Aléssio, R. L. S. (2019).Construções Identitárias de Psicólogos em NASF: Reflexões para a Prática Profissional. Psicologia: Ciência e Profissão, 39, 1-15.https://doi.org/10.1590/1982-3703003174637

How to cite:Vasconcelos, F. G., \& Aléssio, R. L. S. (2019).Identity Constructions of Psychologists in NASF: Reflections for Professional Practice. Psicologia: Ciência e Profissão, 39, 1-15. https://doi.org/10.1590/1982-3703003174637

Cómo citar:Vasconcelos, F. G., \& Aléssio, R. L. S. (2019). Construcciones Identitarias de Psicólogos en NASF: Reflexiones para la Práctica Profesional. Psicologia: Ciência e Profissão, 39, 1-15.https://doi.org/10.1590/1982-3703003174637 